\title{
Spectrum of Injuries Inflicted and their Consequences Following Wild Animals Attack: Retrospective Study
}

\author{
Hamal RR, Lamichhane S \\ Department ofOrthopaedics, College of MedicalSciences(COMS), Chitwan, Nepal \\ Received: August 19, 2020 \\ Accepted: November 25, 2020 \\ Published: December 30, 2020 \\ Cite this paper: \\ HamalRR,LamichhaneS. Spectrum of Injuries Inflicted and their Consequences Following Wild Animals Attack:Ret- \\ rospective Study. Nepal Journal of Medical Sciences 2020;5(2):16-20. http://dx.doi.org/10.3126/njms.v5i1.36706
}

\begin{abstract}
Introduction: Human-wildlife conflict in the Himalayan kingdom of Nepal is the major concern in and around the protected area due to dramatic change in the ecosystem which includes a rise in human population and their basic requirements that leads to loss of natural habitat for agriculture farming and residential purpose. On the other hand, successful conservation programme in some protective areas leads to a rise in a number of wildlife. This conflict ultimately leads to damage of the crops, property, livestock and the most important human casualties which is the main focus of this study.
\end{abstract}

Methods: This is a hospital-based retrospective study in which 32 patients visiting the emergency and outpatient department with a history of wild animals attack were included. Advanced trauma life support protocol for polytrauma patients was followed. Anti tetanus and anti-rabies prophylaxis given followed by antibiotics coverage. Operative and multidisciplinary interventions were made as per the requirement.

Results: Out of the total 32 patients, soft tissue injury Oestern-Tscherne grade 3 was the commonest type of injury seen in 19(59.4\%) of the cases, the commonest species involved was rhinoceros $8(25 \%)$. The anatomical site most commonly involved was lower limb $10(31.3 \%)$. Fracture fixation was required in $8(25 \%)$ cases. The commonest complication was wound infection in $5(16 \%)$ cases.

Conclusion: This research elaborates the current scenario of human-wildlife conflict, facilitates to identify and face the common type of injuries, their complications, the role of a multidisciplinary approach and hence implement certain treatment protocols as a part of effective management to avoid major consequences to public health.

Keywords: Human Wildlife Conflict; Multidisciplinary Approach; Protective Area

Correspondence to: Dr. Rajkumar Ravi Hamal

Department of Orthopaedics

College of Medical Sciences (COMS)

Chitwan, Nepal

Email: ravihamal@gmail.com

Licensed under CC BY 4.0 International License which permits use, distribution and reproduction in any medium, provided the original work is properly cited 


\section{INTRODUCTION}

Human beings attacked by wild animals in and around conservation area is a common scenario all over the world. The spectrum of casualties varies from minor injuries to serious fatal cases specifically to the person involved as well as to their family, relatives, to the social, economic, health and psychological status and at the minimum damage of various properties. ${ }^{1}$ Dramatic rise in population forces humans to live in the areas closer to the natural habitat of wild animals making them vulnerable to their attack. ${ }^{2}$ Human requirements that leads to conversion of the wildlife habitats for agricultural, farming and residential purpose is one of the major cause for human-wildlife conflict. ${ }^{3}$ Change in the ecosystem signified by successful conservation program in some protective areas leading to rising in the number of wildlife is another major cause of the conflict. ${ }^{4}$ Due to lack of regular check and inadequate implementation of law and policies there are many cases of unauthorized haunting and wild animals harassment as well. ${ }^{5}$ This generates a conflict between human and wildlife as well as between humans about wildlife. ${ }^{6}$ The resultant effect is in the form of damage to the crops, property, livestock and the most important human casualties which is the main focus of this study. Mitigation measures include compensatory payments made to the victims or their families and through depredation of the wild animals that are frequently involved.?

In the context of this study, the human-wildlife conflicts are confined to the vicinity in and around the Chitwan National Park (CNP) which was established in 1973. The territory of CNP comprises four administrative districts: Chitwan, Nawalparasi, Parsa and Makwanpur. It was granted the status of a world heritage site by UNESCO in the year $1984 .{ }^{8}$ The park consists of a total area of 953 square $\mathrm{km}$ as the first protected area of Nepal. ${ }^{9}$ Prevention and management of these injuries are of paramount importance. The treatment part requires a multidisciplinary approach involving orthopaedic as well as plastic surgeon, microbiologist, general surgeon, anes- thesiologist, cardiothoracic and vascular surgeon, psychiatrist and others. ${ }^{10}$ The victims were stabilized first then after the soft tissue including vascular and neurological injury, bony injuries, post-traumatic stress disorder, injury complications and their probabilities are addressed. ${ }^{11}$ The objective of this study is to determine the wildlife species involved, anatomical regions affected, types of injuries and their complications and to determine various treatment modalities.

\section{METHODS}

A retrospective study was conducted from January 2017 to January 2020 among all the patients received in the emergency department, College of Medical Sciences-Teaching Hospital, Chitwan, following wild animals attack. Very few with minor injuries who directly come to the outpatient department were addressed then and there. Advanced trauma life support protocol were followed for polytrauma patients. Necessary investigations were done. Anti tetanus prophylaxis were given after checking the tetanus status in patients with minor injuries to major trauma. Anti rabies prophylaxis were given after taking proper history and examination depending upon the wild animal involved and type of injury and attack. The patients were treated with proper antibiotic coverage. Thorough debridement, lavage and dressing of the wounds were done. Once stabilized patients were shifted to respective departments. Most of the patients needed multidisciplinary intervention which was made possible after coordination with other concerned departments. All operative interventions were made following proper counselling and after obtaining written informed consent. Approval from IRC was obtained. All the demographic information were collected in the performed pro forma as a data collection tool. All the soft tissue injury were assessed as per Oestern - Tscherne classification and open fractures were assessed as per the Gustilo-Anderson classification. ${ }^{12,13}$ The data were entered, refined and analyzed using Microsoft Word 2010 and SPSS version 20 . The data were tabulated and presented us- 
ing appropriate tables, graphs and pictures.

\section{RESULTS}

A total of 32 patients with a history of wild animals attack were included in the study. There were 22(68.8\%) male and 10(31.3\%) female with male to female ratio of $2.2: 1$. The mean age of 40.6 years (SD:15.29) range (14 $-75)$ years. The maximum number of patients were from Chitwan 13(40.6\%), Nawalparasi $7(21.9 \%)$, Parsa 4(12.5\%) districts and farmer by occupation $19(59.4 \%)$ followed by local tourists $6(18.8 \%)$, students $6(18.8 \%)$ and tourist guide $1(3.1 \%)$. The commonest species involved in the attack was rhinoceros $8(25 \%)$ as shown in table 1.

Table 1: Wild Animals

\begin{tabular}{ccc} 
Animals & Frequency & Percentage \\
\hline bear & 4 & 12.5 \\
blue bull & 2 & 6.3 \\
crocodile & 2 & 6.3 \\
deer & 1 & 3.1 \\
elephant & 3 & 9.4 \\
fox & 2 & 6.3 \\
leopard & 2 & 6.3 \\
monkey & 1 & 3.1 \\
rhinoceros & 8 & 25.0 \\
tiger & 3 & 9.4 \\
wild boar & 4 & 12.5 \\
Total & 32 & 100.0 \\
\hline
\end{tabular}

The anatomical site most commonly involved was lower limb 10(31.3\%) followed by upper limb 8(25\%), both upper and lower limb $8(25 \%)$ and back $6(18.8 \%)$ cases as shown in figure 1 . As per the various injury patterns inflicted 19(59.4\%) patients had soft tissue injury Oestern - Tscherne grade 3 and 3(9.4\%) had grade 2 injury, $9(28.1 \%)$ patients had a bony injury. A single case was recorded for forearm amputation (3.1\%) as shown in table 2.Among the 9 bony fracture patients, 6 patients had open fracture with various GustiloAnderson types as illustrated in table 3 were as 3 patients had a close fracture.

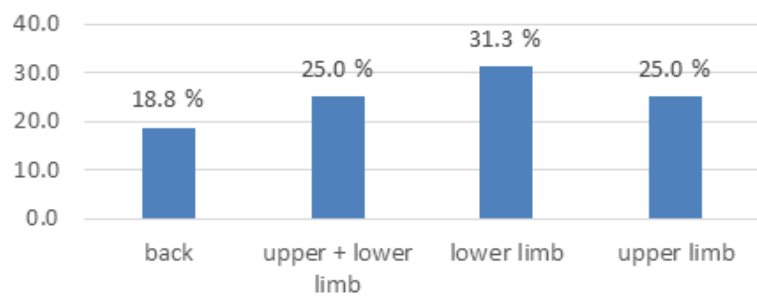

Figure1: Anatomical site

Table 2: Injury Type

Injury Type Frequency Percentage

amputation 3.1

calcaneum fracture $\quad 1 \quad 3.1$

femur fracture

6.3

floating knee

3.1

forearm fracture

3.1

$\mathrm{O}$-T grade 2

9.4

$\mathrm{O}-\mathrm{T}$ grade 3

59.4

phalynx fracture

6.3

tibia fracture

6.3

Total

32

100.0

Table 3: Gustilo-Anderson

\begin{tabular}{lrr} 
G-A Type & Frequency & Percentage \\
II & 3 & 9.4 \\
IIIA & 1 & 3.1 \\
IIIB & 2 & 6.3 \\
None & 26 & 81.3 \\
Total & 32 & 100.0 \\
\hline
\end{tabular}

Among the associated injuries 6(19\%) patients had facial injuries followed by chest injury in $4(12 \%)$ and blunt abdomen trauma in $2(6 \%)$ patients as illustrated in figure 2 . All the patients received thorough debridement, lavage with dressing however fracture fixation was required only in $8(25 \%)$ cases. Wound infection was the commonest complication seen in 5(16\%) patients followed by delayed union $1(3 \%)$ and joint stiffness in $1(3 \%)$ case as shown in figure 3 . Repeated surgery were required in $9(28.1 \%)$ cases because some underwent lifesaving procedures first while the others were posted for redebridement due to infection followed by definitive treatment. 


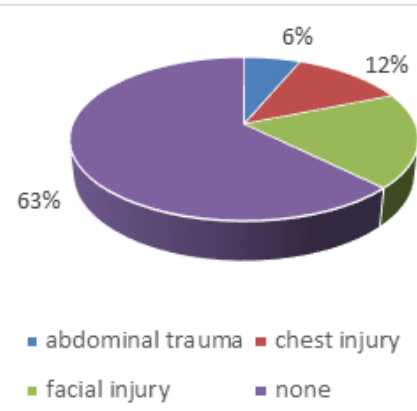

Figure 2: Associated injuries

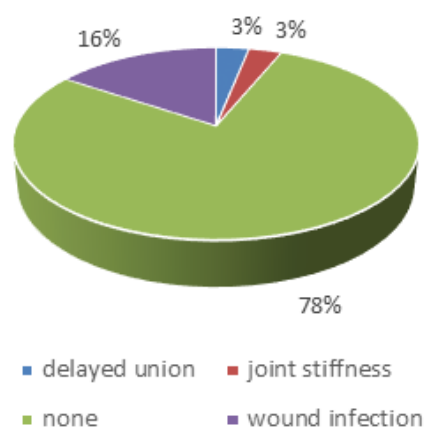

Figure 3: Complications

\section{DISCUSSION}

According to the data out of a total of 32 cases, most of the victims were farmer $19(59.4 \%)$ by occupation residing near to the buffer zone of the protective area. Hence people living near to or doing their works nearby the protective area were more prone to attack by wild animals.

The commonest species involved in this study is rhinoceros $8(25 \%)$. As per Ruda et al. in their study data from 2003 to 2013, rhinoceros dominated the human attack 126(38\%) cases out of 329 wild attacks. ${ }^{8}$

In this study involvement of lower limb $10(31.3 \%)$ was more common than other anatomical sites comparable to the study conducted by Bajracharya in which thigh and hip regions were most commonly involved $(33.33 \%)$ followed by arm and shoulder region $(21.83 \%){ }^{14}$

As per the study out of 32 cases, 9 patients had a bone fracture out of which 6 patients had an open fracture and 3 patients had a closed fracture. As per Bhat et al out of 21 patients, total fractures were 27 out of which 24 were open and 3 closed along with the injuries to the face and scalp. ${ }^{4}$

Except for the orthopaedic injuries other associated injuries were also recorded. As per the data facial and scalp injuries were most common followed by chest injury and blunt abdominal trauma which were addressed after proper coordination and effective management from the various concerned departments. Hence the focus of this study on multidisciplinary approach and intervention can be justified.

All the patients underwent debridement, lavage and dressing of the wounds whereas $8(25 \%)$ patients underwent fracture fixation. Wound infection was the commonest complication seen in 5(16\%) patients despite prophylactic intravenous antibiotics signifying the role of redebridement. Resurgery was performed on $9(28.1 \%)$ patients.

As far as the limitations are concerned the study population involves only a single health institution and hence does not represent the whole scenario of the human-wildlife conflict of this region. Also, the main focus of this study is the human casualties and their management rather than the damage of crops and properties and last but not least casualties of nature and its wildlife.

\section{CONCLUSION}

The resultant effect of human-wildlife conflict is in the form of damage of the crops, property, livestock and the most important human casualties in the form of soft tissue: vascular, neurologic and others, bony, post-traumatic stress and multidisciplinary injuries and even death altering the social, economic and psychological status of the victim and its family. As a result, we are bound to discuss and implement the preventive measures and accordingly plan the management part to avoid the major threat to public health.

\section{CONFLICT OF INTEREST}

None

\section{SOURCES OF FUNDING}

None 


\section{REFERENCES}

1. Silwal T, Kolejka J, Sharma RP. Injury severity of wildlife attacks on humans in the vicinity of Chitwan national park, Nepal. J Biodivers Manage Forestry. 2016;5(1). https://doi.org/10.4172/2327$\underline{4417.1000154}$

2. Moten TL, Bhat TA, Gulzar A, Mir A, Mir F. Casualties of human wildlife conflict in Kashmir valley, India; a neglected form of trauma: our 10 year study. Int J Res Med Sci. 2017;5(5):1898-1902. https://doi. org/10.18203/2320-6012.ijrms20171814

3. Gurung B, Smith JL, McDougal C, Karki JB, Barlow A. Factors associated with human-killing tigers in Chitwan National Park, Nepal. Biological Conservation. 2008;141(12):3069-78. https://doi. org/10.1016/j.biocon.2008.09.013

4. Bhat T.A, Gulzar A, Bhat A.A, Bhat Ta.A, Ali Z. A review of upper limb injuries in bear maul victims:Consistent pattern and inverse relationin severity with facial and scalp injuries. Chin J Traumatol. 2018;21:38-41. https://doi.org/10.1016/j. cjtee.2017.11.001

5. Stoen OG, OrdizA, Sahlen V, Arnemo J.M, Saebo S, Mattsing G. Brown bear (Ursus arctos) attacks resulting in human casualties in Scandinava 1977-2016; management implications and recommendations. Plos one. 2018;13(5):e0196876. https:// doi.org/10.1371/journal.pone.0196876

6. Madden F.M. The growing conflict between humans and wildlife: law and policy as contributing and mitigating factors. $J$ Int Wildl Law Policy. 2008;11:189-206. https://doi. org/10.1080/13880290802470281

7. Dhungana R, Savini T, Karki J.B, Bumrungsri S. Mitigating human-tiger conflict: an assessment of compensation payments and tiger removals in Chitwan national park, Nepal. Tropical conservation science. 2016;9(2):776-87. https:// doi.org/10.1177/194008291600900213

8. Ruda A, Kolejka J, Silwal T. GIS-Assisted prediction and risk zonation of wild life attacks in the Chitwan national park in Nepal. Int J Geo-Inf. 2018;7(369):1-21. https://doi.org/10.3390/ijgi7090369

9. Lamichhane B.R, Persoon G.A, Leirs H, Poudel S, Subedi N, Pokheral C.P et al. Spatio-temporal patterns of attacks on human and economic losses from wildlife in Chitwan national park, Nepal. PloS One. 2018;3(4):e0195373. https://doi. org/10.1371/journal.pone.0195373

10. Nabi D.G, Tak S.R, Kangoo K.A, Halwai M.A. Increasing incidence of injuries and fatalities inflicted by wild animals in Kashmir. Injury. 2009;40(1):87-9. https:// doi.org/10.1016/j.injury.2008.06.042

11. Shepherd S.M, Mills A, Shoff W.H. Human attacks by large felid carnivores in captivity and in the wild. Wilderness Environ Med. 2014;25(2):220-30. https:// doi.org/10.1016/j.wem.2014.01.005

12. Oestern H. J, Tscherne H. Pathophysiology and classification of soft issue injuries associated with fractures. In: Tscherne H,editor. Fractures with soft tissues injuries. New York: Springer-Verlag;1984:1-9. https://doi.org/10.1007/978-3-64269499-8 1

13. Paul HK, Seth SL. Gustilo-Anderson Classification. Clin Orthop Relat Res. 2012;470(11):3270-4. https://doi. org/10.1007/s11999-012-2376-6

14. Bajracharya S. Farm related and wild animals inflicted injuries related to orthopaedics: Epidemiology and prospects for control. Journal of Nobel medical college. 2017;6(2):53-7. https://doi.org/10.3126/ jonmc.v6i2.19571 